\title{
Nucleus accumbens mediates relative motivation for rewards in the absence of choice
}

\author{
John A. Clithero', , Crystal Reeck ${ }^{2,3}$, R. McKell Carter ${ }^{2}$, David V. Smith ${ }^{2,3}$ and Scott A. Huettel ${ }^{2,3 *}$ \\ Department of Economics, Duke University, Durham, NC, USA \\ 2 Center for Cognitive Neuroscience, Duke University, Durham, NC, USA \\ ${ }^{3}$ Department of Psychology and Neuroscience, Duke University, Durham, NC, USA
}

\section{Edited by:}

Hauke R. Heekeren, Max Planck Institute for Human Development, Germany

\section{Reviewed by:}

Bernd Weber, Rheinische-FriedrichWilhelms Universität, Germany Alain Dagher, Montreal Neurological Institute and Hospital, Canada

\section{*Correspondence:}

Scott A. Huettel, Duke University, Center for Cognitive Neuroscience, Box 90999 Durham, NC 27708-0999, USA.

e-mail:scott.huettel@duke.edu
To dissociate a choice from its antecedent neural states, motivation associated with the expected outcome must be captured in the absence of choice. Yet, the neural mechanisms that mediate behavioral idiosyncrasies in motivation, particularly with regard to complex economic preferences, are rarely examined in situations without overt decisions. We employed functional magnetic resonance imaging in a large sample of participants while they anticipated earning rewards from two different modalities: monetary and candy rewards. An index for relative motivation toward different reward types was constructed using reaction times to the target for earning rewards. Activation in the nucleus accumbens (NAcc) and anterior insula (aINS) predicted individual variation in relative motivation between our reward modalities. NAcc activation, however, mediated the effects of alNS, indicating the NAcc is the likely source of this relative weighting. These results demonstrate that neural idiosyncrasies in reward efficacy exist even in the absence of explicit choices, and extend the role of NAcc as a critical brain region for such choice-free motivation.

Keywords: anticipation, fMRI, insula, motivation, nucleus accumbens, reward

\section{INTRODUCTION}

"Motivation," taken literally, describes an impulse to movement - as when the expectation of a desired outcome mobilizes someone into action. Motivation can incorporate a variety of drives or internal states that direct behaviors or decisions, ranging from basic homeostatic imbalance correction (Cannon, 1932) to psychosocial needs (Maslow, 1943). While multiple theories of motivation exist, nearly all posit that organisms translate the anticipated hedonic reward for potential outcomes (Berridge, 2004) into the force behind their effort to obtain a reward (Niv et al., 2007; Salamone et al., 2009). Individuals differ in their preferences for rewards, often exhibiting greater motivation in response to some reward modalities compared to others (e.g., striving for income versus personal fulfillment). This heterogeneity in preferences not only impacts choices between rewards, but also shapes, sometimes independently, how much effort will be exerted to receive a single reward in the absence of choice. As most real-world environments involve multiple kinds of rewards, a core challenge for understanding goal-directed behavior lies in understanding how individuals calibrate their expressed effort across rewards of different modalities.

Many neural studies of economic behavior downplay the contributions of motivation to adaptive decision-making. Typical paradigms focus on inferred value signals that predict observable, individual choices between rewards (Platt and Huettel, 2008; Rangel et al., 2008), de-emphasizing the role of motivation for expected outcomes (Kahneman et al., 1997). Nevertheless, both behavioral neuroscience (Berridge, 2004) and behavioral economics (Loewenstein and Lerner, 2003) have highlighted the role that anticipated affect plays in shaping behaviors and preferences (Knutson and Greer, 2008). Although different phases of rewardprocessing, such as anticipation and valuation, are distinct in terms of cognition, the significant overlap in their neural substrates
(Rangel et al., 2008; Balleine and O'Doherty, 2010) implies that idiosyncrasies in within- or across-individual motivation stemming from variable anticipatory responses may lead to subsequent variability in choice-related responses.

Two regions - the nucleus accumbens (NAcc, a subregion of ventral striatum) and the anterior insular cortex (aINS) - have been considered core contributors to idiosyncrasies in reward anticipation (Knutson and Greer, 2008). NAcc and aINS are also both frequently included in neural models of motivation (Delgado, 2007; Craig, 2009; Naqvi and Bechara, 2009), based in part of evidence from non-human primate (Schultz et al., 1992) and rodent (Roitman et al., 2005) studies. However, these regions' anatomical connectivity suggests that they could contribute to different aspects of motivation: aINS is positioned to integrate interoceptive information, while NAcc receives input from both dopaminergic neurons and from multiple cortical regions (Haber and Knutson, 2010). Some theories have emphasized a dissociable role for NAcc and aINS in processing appetitive compared to aversive rewards (Knutson and Greer, 2008), whereas others have posited a dissociation between motivational and reward-processing in these two regions (Craig, 2009). Further, preference-related signals have been found in both NAcc (O'Doherty et al., 2006; Knutson et al., 2007) and aINS (Kim et al., 2011). Strikingly, however, a comprehensive literature review of reward anticipation studies (see Appendix) found no human neuroscience study that dissociated the unique contributions of these two regions to motivation in the absence of choice.

Here, working with expressed instead of inferred preference, we elicited individual differences in relative motivation for two appetitive reward modalities, independent of choices between them. Participants performed a reaction-time task to obtain two rewarding goods: money and candy. The task required participants 
to respond to obtain the rewards, but there were no extrinsic incentives for responding differently to different rewards. Thus, relative response vigor served as a trait measure of relative motivation (Niv et al., 2007). The behavioral task and functional magnetic resonance imaging ( $\mathrm{fMRI}$ ) data allowed functional delineation of contributions to individual differences in relative motivation across reward modalities, with both regions expected to broadly contribute. However, based on its convergent inputs from multiple rewardprocessing regions (Haber and Knutson, 2010), we conjectured that NAcc - but not aINS - would play the primary role in translating differences in motivation into behavior.

\section{MATERIALS AND METHODS \\ PARTICIPANTS}

A total of 65 young adults [ 32 females; age: mean $(M)=24.7$ years, $(\mathrm{SD})=5.9$ years $]$ completed the experiment. Participants were prescreened to rule out psychiatric or neurological illness and to ensure that they were motivated by available candy rewards. Participants gave written informed consent as part of a protocol approved by the Institutional Review Board of Duke University Medical Center. Five of the 65 participants were excluded prior to data analyses - three for excessive head motion ( $>2 \mathrm{~mm}$ ), one due to scanner error, and one because of failure to complete the task-leaving a final sample of 60 participants.

\section{EXPERIMENTAL PROCEDURE}

The experimental session comprised task instructions and training outside the scanner, the fMRI session using the reward anticipation task (described below), two other subsequent reward-related choice tasks (not considered here), and payment based on performance.

Each trial (Figure 1) began with a 1000-ms cue indicating the potential reward for that trial. Participants worked to obtain rewards that varied in magnitude and modality across five conditions: \$5 (BM), \$1 (SM), Large Candy (BC), Small Candy (SC), and Control (Zero, no money or candy). Following a variable delay of 2000-2500 ms, a target (a white triangle) appeared on the screen. Participants responded by pressing a button with their right index finger before the target disappeared. On monetary trials, a sufficiently fast reaction-time (RT) was indicated with a colorful \$ symbol. On candy trials, a sufficiently fast RT was indicated with a cartoon symbol. If their responses were not fast enough to earn a reward for that trial, participants were shown a zero symbol. On control trials, a zero symbol was displayed for all responses regardless of speed. Each functional run consisted of 50 trials, 10 for each category. Trial order was randomized, with a single trial type never allowed to occur more than twice consecutively.

The presentation time of the target was determined by an adaptive algorithm. From the RT on previous trials of each condition, the algorithm estimated a response threshold at which the participant would be successful on approximately $60 \%$ of trials. We emphasize that a different threshold was used for each condition, to allow the assessment of relative motivational differences between them. Stimuli were presented against a gray background. The experiment was controlled using the Psychophysics Toolbox 2.54 (Brainard, 1997) in MATLAB (The MathWorks, Inc.).

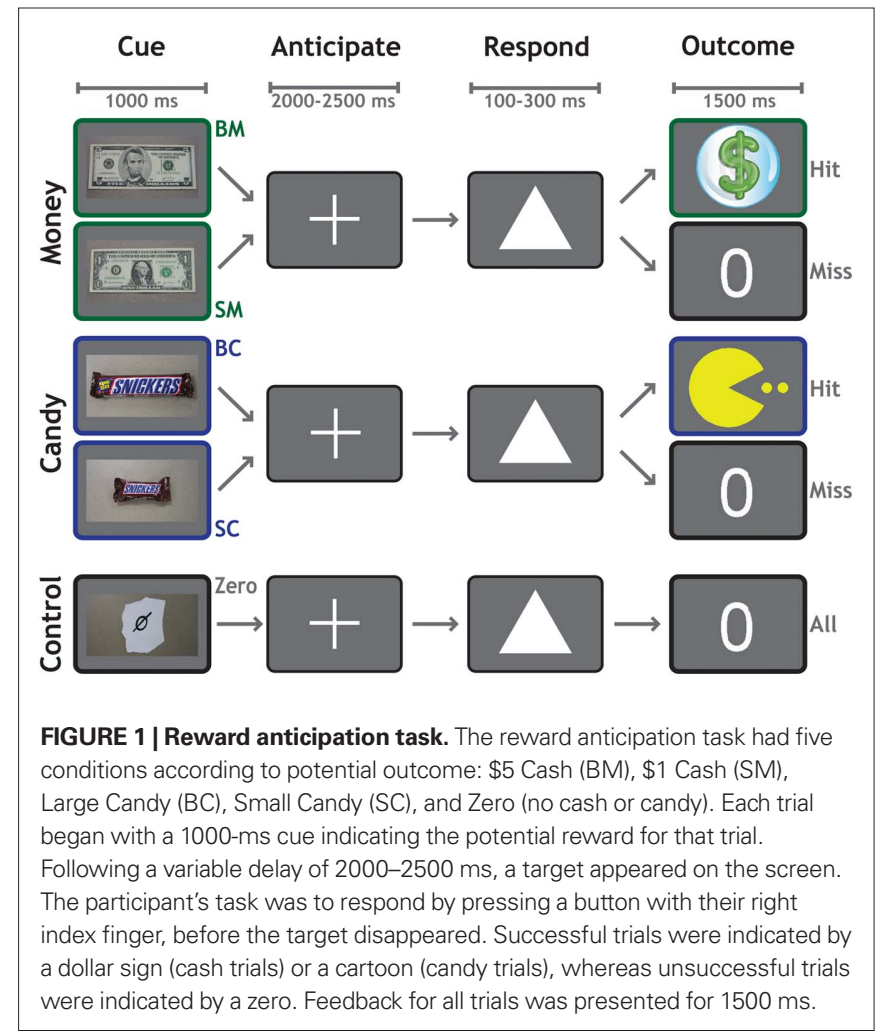

Participants earned at least $\$ 40$ for completing the experimental session and were paid additionally for one randomly chosen trial from each reward modality. All earned monetary rewards were paid in cash at the completion of the experimental session (mean payment $=\$ 58 ; 34$ participants also earned candy given to them at the completion of the session).

\section{IMAGE ACQUISITION}

We acquired fMRI data on a General Electric 4.0-T MRI Scanner with a multi-channel (eight-coil) parallel imaging system. Initial localizer images identified each participant's head position within the scanner. Whole-brain high-resolution $\mathrm{T}_{1}$-weighted coplanar FSPGR structural scans with voxel size $1 \mathrm{~mm} \times 1 \mathrm{~mm} \times 1.9 \mathrm{~mm}$ were acquired for normalization and coregistration. Three runs of images sensitive to blood-oxygenation-level-dependent (BOLD) contrast were acquired using an inverse-spiral pulse sequence (Guo and Song, 2003). Each run consisted of 212 volumes [repetition time $(\mathrm{TR})=2000 \mathrm{~ms}$; echo time $(\mathrm{TE})=27 \mathrm{~ms}$; matrix $=64 \times 64$; field of view $($ FOV $)=240 \mathrm{~mm}$; voxel size $=3.75 \mathrm{~mm} \times 3.75 \mathrm{~mm}$ $\times 3.8 \mathrm{~mm}$; saturation buffer $=6$ volumes $]$ with 34 interleaved axial slices parallel to the axial plane connecting the anterior and posterior commissures.

\section{PREPROCESSING}

Preprocessing used FMRIB Software Library (FSL) Version 4.1.5 (Smith et al., 2004; Woolrich et al., 2009). Functional images were first reoriented and then skull stripped using the FSL brain extraction tool (BET; Smith, 2002). All images were then corrected for inter-scan head motion using FMRIB's Linear Image Registration Tool (MCFLIRT), slice-time corrected, and subjected to a high-pass temporal filter with 
a 100-s threshold (Jenkinson et al., 2002). Time-series statistics for within-participant analyses were performed on native space data and resulting statistical images were spatially normalized using an affine transformation into a standard stereotaxic space (Montreal Neurological Institute, MNI) for group analyses. Each four-dimensional dataset was grand-mean intensity normalized using a single multiplicative factor. Spatial smoothing used an isotropic Gaussian kernel of full-width-half-maximum $6 \mathrm{~mm}$.

\section{FMRI ANALYSES}

Analyses were carried out using FEAT Version 5.98 (FMRI Expert Analysis Tool). Time-series statistical analyses used FILM (FMRIB Improved Linear Model) with local autocorrelation correction (Woolrich et al., 2001). Our first-level (i.e., within-run) analysis model included five regressors for the anticipation period (one for each trial type) with two regressors (hit and miss) for the outcome period of each trial type. The anticipation period was modeled for the variable interval between the disappearance of the trial indicator cue and the appearance of the target. The outcome period was modeled for $1500 \mathrm{~ms}$ following the onset of feedback. Additional regressors were included to account for outlier volumes in each run. A volume was considered an outlier if its root-mean-square (RMS) amplitude exceeded the value of $150 \%$ of the interquartile range of RMS for all volumes in a run.

Second-level analyses (i.e., across-run, within-participant) used a fixed-effects model, while third-level analyses (i.e., across participants) employed a mixed-effects model (FLAME 1) that included the main effects of each regressor from the lower level analysis, along with behavioral covariates (Beckmann et al., 2003; Woolrich et al., 2004). We also completed a repeated-measures $2 \times 2$ analysis of variance (ANOVA) that included four second-level contrasts for each participant: $\mathrm{BM}>$ Zero, $\mathrm{SM}>$ Zero, $\mathrm{BC}>$ Zero, and $\mathrm{SC}>$ Zero.

Unless stated otherwise, all claims of significance in our fMRI whole-brain analyses used a voxel significance threshold of $z>2.3$, and a cluster significance threshold of $p<0.05$, corrected across all voxels included in our whole-brain mask. The region-of-interest
(ROI) analyses targeted bilateral NAcc and aINS. The NAcc ROIs were drawn in each hemisphere on the mean participant anatomical images, according to methods outlined and employed previously (Breiter et al., 1997). The aINS ROI was constructed using 5-mmradius spheres using coordinates [left: $(x, y, z)=(-35,16,-3)$; right: $(x, y, z)=(44,16,-3)]$ derived from a recent meta-analysis (Knutson and Greer, 2008).

Brain images of significance were generated using MRIcron (Rorden et al., 2007). All coordinates in the manuscript are reported in MNI space. Additional regression and mediation analyses were performed in Stata 11.1 (StataCorp).

\section{RESULTS}

BEHAVIOR

Before the experiment, participants identified one of seven different candies (Figure 2A) as the target for their actions; these varied in popularity from the Reese's Peanut Butter Cup (17/60 participants) to the Green \& Black's Milk Chocolate and Vosges Creole (each 3/60 participants). Post hoc analyses failed to identify any significant differences between individuals based on their candy preferences.

We used an adaptive algorithm with individual thresholds for each condition; thus, the proportions of successful responses were similar across all four modality and magnitude conditions (BM trials: $M=58.0 \%, \mathrm{SD}=8.4 \%$; SM trials: $M=55.0 \%, \mathrm{SD}=10.3 \%$; BC trials: $M=53.8 \%, \mathrm{SD}=12.4 \%$; SC trials: $M=54.8 \%, \mathrm{SD}=9.9 \%$ ). Pairwise tests indicated that BM trials were successful significantly more often than those of other conditions (all paired $t$ tests for BM had $p<0.05$ ), reflecting the motivational value of that condition. No other paired comparisons approached significance.

Participant RT data on successful trials varied according to reward condition. Participants exhibited the slowest RT on Zero trials $(M=187.1 \mathrm{~ms}, \mathrm{SD}=23.3)$. Reaction times on $\mathrm{BM}$ trials $(M=173.5, \mathrm{SD}=25.9)$ were significantly faster than Zero trials, as were $\mathrm{SM}$ trials $(M=181.1, \mathrm{SD}=21.9)$. Reaction times on BC trials $(M=181.4, \mathrm{SD}=24.4)$ also were significantly faster

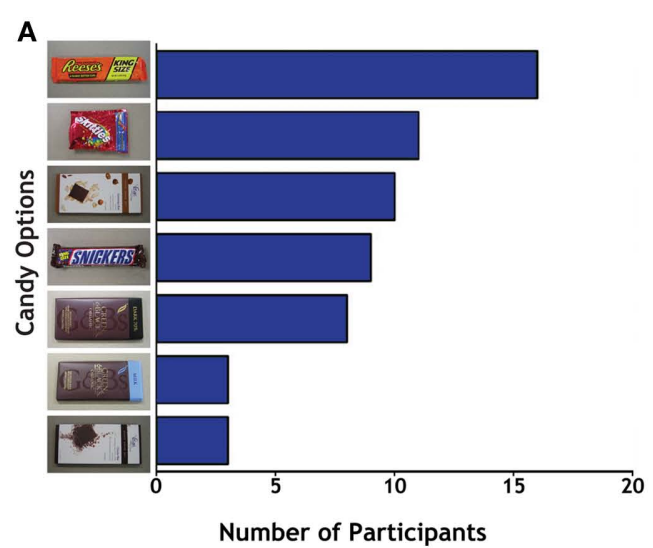

FIGURE 2 | Behavioral preferences for candy and money. (A) Distribution of results for candy selection. We offered seven different candies to participants, all of whom indicated that they desired candy rewards before enrolling in the study. Reese's Peanut Butter Cup (top) was the most popular (17 out of 60), although

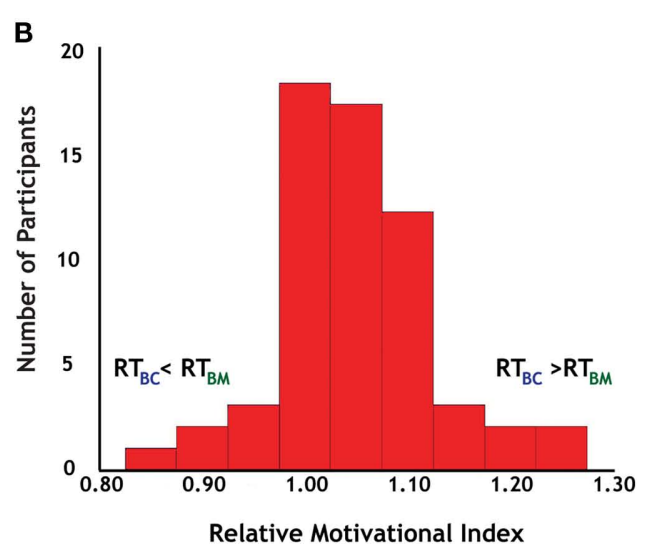

all seven options were chosen by multiple participants, indicating a distribution of candy preferences in the participant sample. (B) Distribution of the relative motivational index (RMI), calculated as the ratio of reaction times on successful Big Candy (BC) and Big Money (BM) trials. 
than Zero. All tests were $p<0.01$. This relationship was not true for SC trials $(M=185.6, \mathrm{SD}=21.9)$, though. There was a main effect of modality $[F(1,59)=24.73, p<0.001]$ and reward magnitude $[F(1,59)=19.12, p<0.001]$, but there was not a significant modality (money, candy) $\times$ magnitude (big, small) interaction $[F(1,59)=1.95, p>0.15]$.

To measure interparticipant variability in motivation across reward modalities, we calculated the ratio of successful-trial RT (Carter et al., 2009) for $\mathrm{BC}$ and $\mathrm{BM}$ trials $\left(\mathrm{RT}_{\mathrm{BC}} / \mathrm{RT}_{\mathrm{BM}}\right)$ as our relative motivational index (RMI). Reaction times on the larger magnitude trials were used in the computation of this index based on the overall faster reaction times to larger rewards, which indicated that motivation was generally highest on these trials. Values of RMI greater than 1.0 indicate greater relative motivation for money than for candy rewards (Figure 2B). The mean for our RMI was 1.05 $(\mathrm{SD}=0.08)$. Tests for normality on our RMI distribution [skewness (third moment $)=0.30, p=0.30$; kurtosis (fourth moment $)=4.31$, $p<0.05$; joint test: $\chi^{2}=4.94, p=0.09$ ] indicated a general trend for participants to have stronger motivation for money trials. This bias in relative motivation to monetary rewards was also evident in response patterns to smaller magnitude rewards, with successfultrial RT for SC and SM trials $\left(\mathrm{RT}_{\mathrm{SC}} / \mathrm{RT}_{\mathrm{SM}}\right)$ correlating with $\mathrm{RMI}$ $(r=0.26, p<0.05)$ and exhibiting similar mean and variance $(M=1.03, \mathrm{SD}=0.08)$.

We further investigated RT in terms of effects of time on behavior. Hit rate and RT were initially examined using separate repeatedmeasures ANOVAs with condition (BM, SM, BC, SC) and task block (first, second, or third run). Task block did not interact with condition for either hit rate $(p>0.4)$ or RT $(p>0.2)$, indicating that the relative motivation effects were stable over the course of task performance.

Although all participants were able to select any of the seven candies for their experimental session, the candies were of varying commercial value, with some relatively inexpensive (Reese's, Snickers, Skittles) and some relatively more expensive (both types of Green \& Black's and Vosges). As a check on the fMRI analyses described below, we grouped individuals based on their candy choices (inexpensive and expensive, with groups of $N=36$ and $N=24$, respectively); there were no significant differences between these groups for any of the main contrasts of interest: $\mathrm{BM}>$ Zero, $\mathrm{BC}>$ Zero, and $\mathrm{BM}>\mathrm{BC}$.

\section{MAIN EFFECT OF REWARD ANTICIPATION}

Our primary contrasts of interest were the anticipation-phase contrasts for the four types of reward trials, each compared to the Zero condition. Examining activation in our a priori ROIs, we found that anticipation of rewards robustly increased activation in NAcc and aINS (Figure 3A). Activation on BC trials positively correlated with activation on BM trials in NAcc $(r=0.33, p<0.05)$, and a similar trend was present in aINS (Table 1). Activation in NAcc and aINS were highly correlated on both BM $(r=0.711, p<0.001)$ and BC trials $(r=0.668, p<0.001)$.

Consistent with previous studies of gain anticipation (Knutson and Greer, 2008), both ROIs also exhibited a main effect of reward magnitude, as determined using post hoc $t$ tests (aINS: $t=10.16$, $p<0.001$; NAcc: $t=8.21, p<0.001$ ). Further, we found significant magnitude effects for both monetary $(\mathrm{BM}>\mathrm{SM})$ and candy

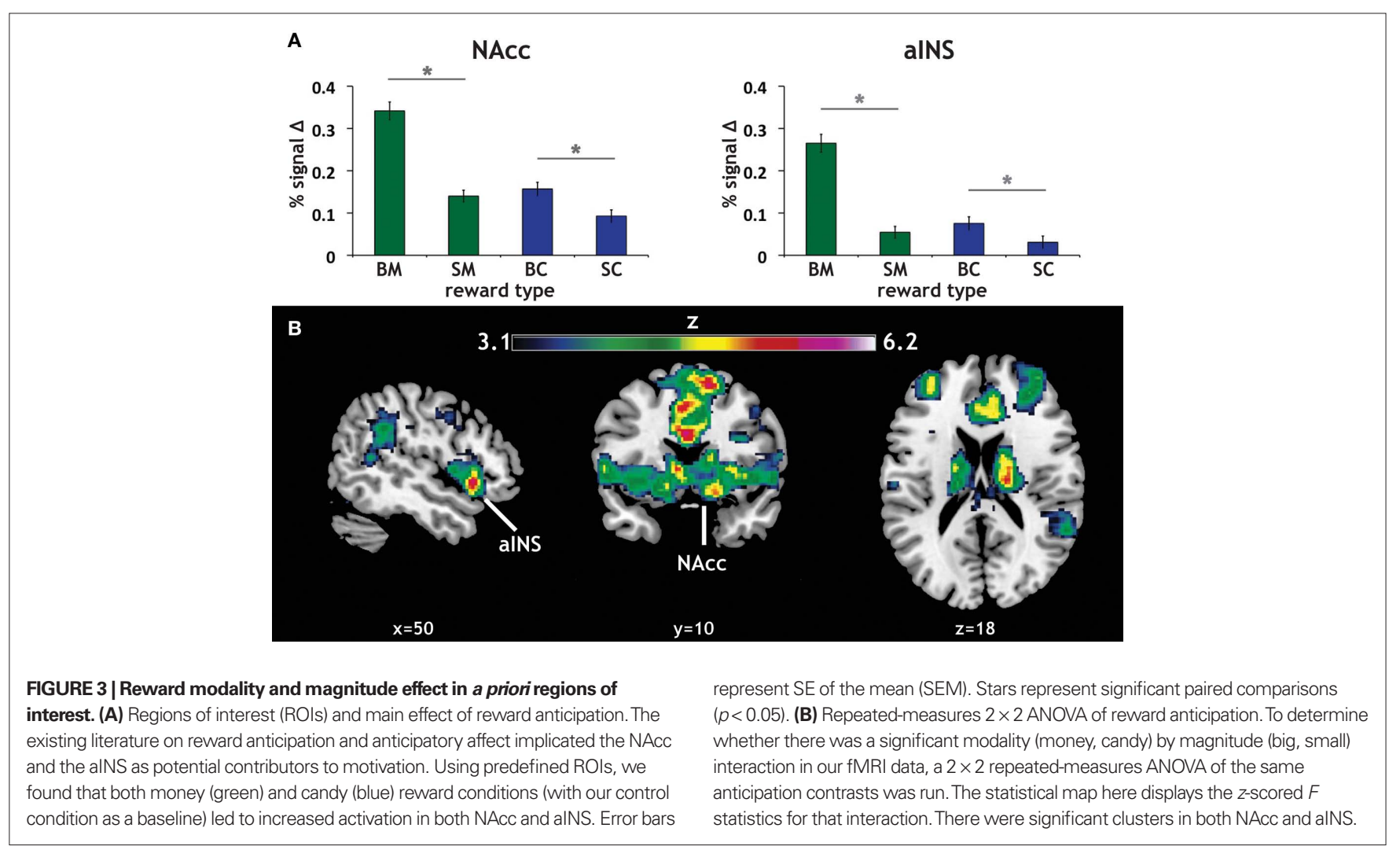


(BC > SC) rewards in both ROIs, with this magnitude effect more pronounced for monetary rewards in both regions as exhibited by a significant modality by magnitude interaction in a repeatedmeasures ANOVA [aINS: $F(1,59)=37.53, p<0.001$; NAcc: $F(1,59)=17.89, p<0.001]$. Paired comparisons of all reward contrasts included in the ANOVA confirmed the direction of this effect.

We additionally examined this same modality (money, candy) by magnitude (big, small) interaction during reward anticipation using a repeated-measures ANOVA of the anticipation contrasts across the whole-brain. The resulting statistical whole-brain map for the interaction (Figure 3B) identified increased activation in a set of regions associated with affective evaluation, including left aINS $[(-36,16,-6) ; z=5.58]$, right putamen $[(18,18,-6) ; z=6.2]$, frontal pole $[(-34,46,14), z=5.2]$, as well as the NAcc (Table 2).

\section{RELATIVE ACTIVATION IN aINS AND NAcc PREDICTS RELATIVE MOTIVATION}

We introduced each participant's RMI (Figure 2B) as a covariate in our whole-brain analyses. RMI significantly correlated with relative activation in both contrasts related to the Big Candy reward (BC > Zero, BC > BM, Figure 4A) within activation clusters that overlapped with both NAcc and aINS ROIs, reflecting larger differential activation during anticipation of candy rewards in participants who

Table 1 | Correlations between alNS and NAcc activation in different conditions.

\begin{tabular}{lllll}
\hline ROI & alNS BC & alNS BM & NAcc BC & NAcc BM \\
\hline alNS BC & - & & & \\
alNS BM & $0.250(0.054)$ & - & & \\
NAcc BC & $0.668(0.000)$ & $0.130(0.323)$ & - & - \\
NAcc BM & $0.094(0.474)$ & $0.711(0.000)$ & $0.331(0.001)$ & - \\
\hline
\end{tabular}

Shown are correlation coefficients for the two big reward categories, big money (BM > Zero) and big candy (BC > Zero), for our two regions of interest, alNS and NAcC. The values used to compute the correlation coefficient are the average parameter values of the contrasts ( $B M>$ Zero and $B C>$ Zero) extracted from the region-of-interest. Mean values and SE of those parameter values are shown in Figure $3 \boldsymbol{A}$. Significance for the correlations $(N=60)$ is shown in parentheses.

Table 2 | Maxima for whole-brain repeated-measures 2 × 2 ANOVA.

\begin{tabular}{llll}
\hline Region & $\boldsymbol{z}$ stat & MNI coordinates $(\boldsymbol{x}, \boldsymbol{y}, \mathbf{z})$ & Cluster \\
\hline Putamen & $\mathbf{6 . 3 0}$ & $(\mathbf{1 8 , 1 8 , - 6 )}$ & $\mathbf{2}$ \\
Anterior cingulate gyrus & 5.95 & $(0,12,28)$ & 2 \\
Anterior cingulate gyrus & 5.94 & $(8,22,28)$ & 2 \\
Anterior cingulate gyrus & 5.94 & $(8,26,22)$ & 2 \\
Thalamus & 5.91 & $(-16,-20,10)$ & 2 \\
Caudate & 5.84 & $(14,2,14)$ & 2 \\
Frontal pole & 5.20 & $(-34,46,14)$ & $\mathbf{1}$ \\
Frontal pole & 5.00 & $(-32,50,20)$ & 1 \\
Frontal pole & 4.94 & $(-34,46,20)$ & 1 \\
Middle frontal gyrus & 3.36 & $(-28,34,26)$ & 1 \\
\hline
\end{tabular}

Repeated-measures $2 \times 2$ ANOVA of reward anticipation. The table here corresponds to the statistical map presented in Figure 3. Cluster maxima are listed in bold. All coordinates listed are in MNI space. responded to them with greater relative vigor. For confirmation, we extracted average contrast values from NAcc (Figure 4B) and aINS (Figure 4C) and again found the same relationship with both the BC $>$ Zero contrast (NAcc: $r=-0.40, p<0.01$; aINS: $r=-0.33$, $p<0.01$ ), as well as for the BC $>$ BM contrast (NAcc: $r=-0.29$, $p<0.05$; aINS: $r=-0.23, p=0.07$ ). This relationship did not hold for contrasts related to the monetary rewards (e.g., for BM > Zero) in either aINS $(p>0.90)$ or NAcc $(p>0.80)$. These findings suggest that the relationship between relative response vigor and neural activation during reward anticipation is driven by neural anticipatory activation to candy reward trials.

We also constructed an analogous index for SC and SM trials $\left(\mathrm{RT}_{\mathrm{SC}} / \mathrm{RT}_{\mathrm{SM}}\right)$, and entered it as a covariate in our across-participant analyses for the $\mathrm{BC}>$ Zero contrast. A small-volume correction of the bilateral NAcc mask was applied before employing cluster significance threshold of $p<0.05$ and a voxel significance threshold of $z>2.3$. The peak value of $z=2.56$ for the four voxel cluster surviving that threshold was located at $(x, y, z)=(14,14,-8)$ in left NAcc. No analogous effect was found in aINS.

As a test of whether activation in our two ROIs predicted our motivational index, we used general linear regression analyses to evaluate whether RMI can be predicted from the magnitude of the BC and BM (> Zero) contrasts for both NAcc and aINS (Table 3). When all four contrasts were included in a single model, only the BC contrast for NAcc significantly predicted an individual's RMI. Given the positive skew in the RMI, we performed a robust regression of the same model, which allowed us to compute SE that do not assume normality. Again, the only one of the four regressors in the model to achieve statistical significance $(p<0.05)$ was the BC contrast in NAcc.

\section{BETWEEN-GROUP NEURAL DIFFERENCES IN NAcc}

As a confirmation of the above analyses, which used the continuous variable of RMI, we classified each participant into either a "money group" $(N=46)$ or a "candy group" $(N=14)$ based on which category evoked faster reaction times (Figure 2B). The magnitude of the $\mathrm{BM}>\mathrm{BC}$ contrast was greater in the money group than in the candy group (Figure 5), with the global maximum for the between-group effect found in NAcc (Table 4). These results show that our primary analyses are robust to partitioning our sample into two distinct groups, as opposed to individuals drawn from a continuum.

Given that the relative contrast of $\mathrm{BM}>\mathrm{BC}$ significantly differed (money group: $M=0.18$; candy group: $M=0.06$; $t=2.32$, $p<0.05$ ), we extracted the main effect contrasts of both $\mathrm{BC}>$ Zero and $\mathrm{BM}>$ Zero for that peak, for both groups. The result here was striking: we found no significant differences in $\mathrm{BM}>$ Zero $(p>0.70)$ between the two groups, but did find significant differences between the two groups in the $\mathrm{BC}>$ Zero contrast (money group: $M=0.10$; candy group: $M=0.20 ; t=2.94, p<0.001)$. We found a parallel result in the behavioral data: the candy group exhibited significantly faster RT than the money group on the BC trials $(t=1.98, p=0.05)$, but there was no difference between groups on the BM trials $(p>0.5)$. This result supports the notion that money is a more universally motivating reward - and thus less likely to evoke heterogeneous neural or behavioral response across individuals. 


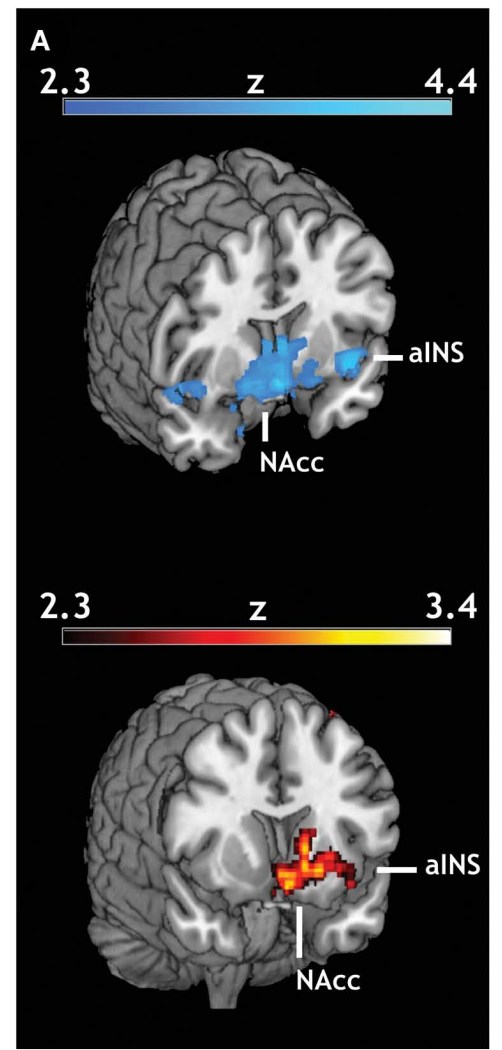

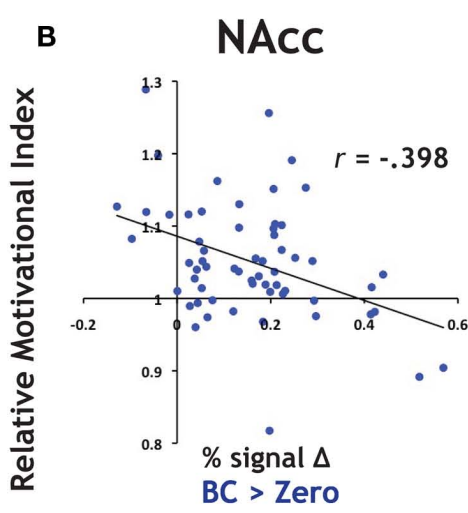

NAcC

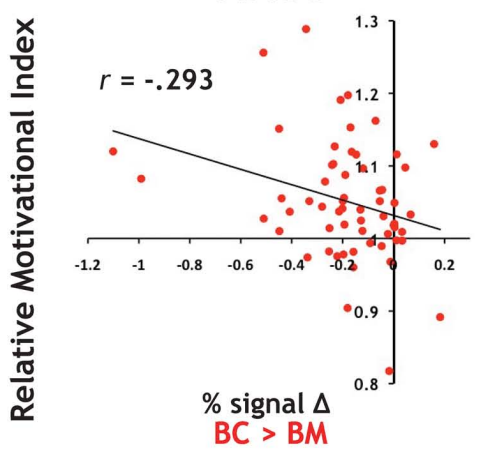

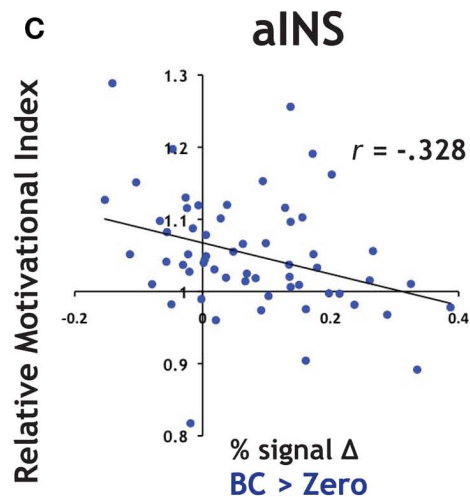

aINS

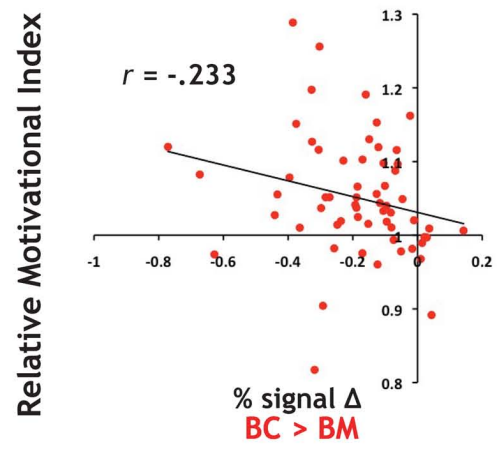

FIGURE 4 | Individual differences in an index of relative motivation covaries with neural signal during reward motivation. (A) Statistical whole-brain maps for anticipatory activation that covaried with motivational index. In order to expand our analyses to include individual differences in reward sensitivity, we introduced each participant's motivational measure (i.e., the relative motivational index, RMI) as a covariate in the across-participant analysis of our reward anticipation task. For both of our a priori regions of interest, (B) the NAcc and $(\mathbf{C})$ the alNS, we found a significant relationship between $\mathrm{RMI}$ and both $\mathrm{BC}>$ Zero (blue) and $\mathrm{BC}>\mathrm{BM}$ (red).
Table 3 | NAcc BOLD signal predicts motivational index across participants.

Regression of RMI on ROI reward anticipation contrasts

\begin{tabular}{lllllll}
\hline RMI & Coefficient & (SE) & \multicolumn{1}{l}{$\boldsymbol{t}$} & $\boldsymbol{p}$ & \multicolumn{2}{c}{$\mathbf{9 5 \%}$ Conf. intv. } \\
\hline aINS BC & 0.0001 & $(0.126)$ & 0.01 & 0.995 & -0.252 & 0.254 \\
alNS BM & -0.077 & $(0.100)$ & -0.78 & 0.441 & -0.277 & 0.122 \\
NAcc BC & -0.266 & $(0.110)$ & -2.42 & 0.019 & -0.486 & -0.045 \\
NAcc BM & 0.105 & $(0.074)$ & 1.42 & 0.163 & -0.044 & 0.254 \\
Constant & 1.077 & $(0.021)$ & 51.40 & 0.000 & 1.035 & 1.119 \\
R $^{2}$ & 0.199 & $F(4,55)$ & 3.42 & & & \\
Adj R & 0.141 & $p$ & 0.015 & & & \\
\end{tabular}

We regressed $R M I$ on the four BOLD large magnitude contrasts from our two ROIs. This analysis provided convergent evidence for our covariate analysis (Figure 4), as BC > Zero contrasts were correlated with RMI. Importantly, only NAcc had a significant effect $(p<0.05)$. Reported coefficient estimates are unstandardized. These estimates were also robust to skewness tests and SE estimates that did not assume normality of RMI (see Results).

To account for the different numbers of participants in our candy and money groups, we also ran permutation tests on the difference between the average contrast value for the two groups
(10,000 replications, with groups of $N=14$ and $N=46)$. For the NAcc peak, both the $\mathrm{BM}>\mathrm{BC}$ contrast $(p<0.01)$ and the $\mathrm{BC}>$ Zero $(p<0.01)$ were robust to the permutation tests; i.e., fewer than $1 \%$ of the permutations into groups yielded differences that were greater than the true values. The same was also true for our bilateral NAcc ROI in BM $>$ BC $(\mathrm{p}<0.05)$ and BC $>$ Zero $(p<0.01)$.

\section{NAcc MEDIATES THE RELATIONSHIP BETWEEN aINS AND MOTIVATION}

Mediation analyses were conducted to establish whether NAcc and aINS represent the same properties of the individual measure of relative motivation, or if one region's information subsumes the other's information. A mediation analysis (Baron and Kenny, 1986) can address whether one of our two ROIs mediates the effect of the other ROI on the RMI. Employing the BC > Zero contrast, we found that NAcc activation mediated $66 \%$ of the effect of aINS activation on RMI values, reducing its influence to insignificance (Figure 6A). Importantly, the converse was not true: aINS activation did not mediate the effect of NAcc activation on RMI (Figure 6B). In line with the regression results from above where RMI was regressed on contrasts from the two ROIs (Table 3 ), this mediation effect was not present (in either direction) for the BM contrasts. These results indicate the primacy of neural signals in the NAcc - compared to aINS - for relative motivation between modalities. 


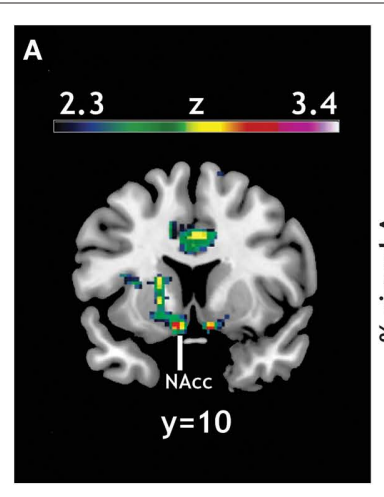

B

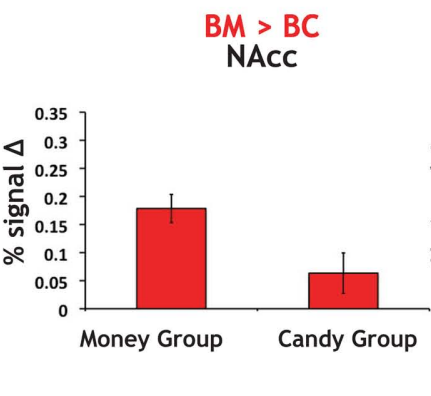

$B M>B C$

C
FIGURE 5 | Group differences in activation for relative reward anticipation contrast. (A) We grouped our participant population into two categories based on RMI. An index value less than one (more than one) implied a relatively greater motivation for candy (money), so we divided our participant pool using this threshold. Using a whole-brain correction, we found significantly greater activation in the BM > BC contrast for our money group $(N=46)$ than in our candy group ( $N=14$ ). (B) The average parameter estimates for the money and candy groups in the NAcc region found in the whole-brain analysis for the relative $\mathrm{BM}>\mathrm{BC}$ contrast. (C) We extracted both $\mathrm{BC}>$ Zero and $\mathrm{BM}>$ Zero contrasts for the NAcc from the group test, for both groups. We found no significant differences in BM between the two groups, but did find significant differences between the two groups in the BC contrast.
Table 4 | Maxima for candy group and money group differences.

\begin{tabular}{|c|c|c|c|}
\hline Region & z stat & MNI coordinates $(x, y, z)$ & Cluster \\
\hline Nucleus accumbens & 3.37 & $(-8,8,-12)$ & 3 \\
\hline Operculum cortex & 3.35 & $(34,30,-2)$ & 3 \\
\hline Nucleus accumbens & 3.27 & $(12,6,-12)$ & 3 \\
\hline Thalamus & 3.20 & $(4,-8,-2)$ & 3 \\
\hline Nucleus accumbens & 3.18 & $(8,18,-10)$ & 3 \\
\hline Putamen & 3.16 & $(-22,16,0)$ & 3 \\
\hline Anterior cingulate gyrus & 3.29 & $(-6,24,22)$ & 2 \\
\hline Posterior cingulate gyrus & 3.23 & $(-2,-28,22)$ & 2 \\
\hline Anterior cingulate gyrus & 3.06 & $(8,6,36)$ & 2 \\
\hline Anterior cingulate gyrus & 3.00 & $(-12,6,36)$ & 2 \\
\hline Anterior cingulate gyrus & 2.97 & $(-6,4,34)$ & 2 \\
\hline Anterior cingulate gyrus & 2.92 & $(0,16,34)$ & 2 \\
\hline Supplementary motor cortex & 3.16 & $(-2,-12,56)$ & 1 \\
\hline Superior frontal gyrus & 3.14 & $(-14,4,70)$ & 1 \\
\hline Superior frontal gyrus & 3.11 & $(24,2,66)$ & 1 \\
\hline Supplementary motor cortex & 3.06 & $(4,-6,62)$ & 1 \\
\hline Superior frontal gyrus & 2.98 & $(20,0,64)$ & 1 \\
\hline Supplementary motor cortex & 2.93 & $(6,2,66)$ & 1 \\
\hline
\end{tabular}

Using RMI, our measure of relative motivation, to divide our participant population, we found significantly greater activation in several regions in the $B M>B C$ contrast for our money group $(N=46)$ than in our candy group $(N=14)$. The table here corresponds to the statistical map presented in Figure 5. Cluster maxima are listed in bold. All coordinates listed are in MNI space.

\section{DISCUSSION}

Although both NAcc and aINS have been typically linked through a common role in anticipatory motivation (Knutson and Greer, 2008), our findings indicate that those brain regions make distinct contributions to the relative motivation associated with different reward modalities. Unlike choice-based studies that focus on valuation and outcome (Rangel and Hare, 2010), we focus on antecedent signals ahead of reward receipt and free from choice between rewards. We establish a correspondence between anticipatory neural signals and an index of relative response vigor to make claims about relative motivation. Our results demonstrate that information predictive of heterogeneity in relative motivation is robustly represented in the NAcc. While changes in aINS activation also predict our motivational index, we establish that NAcc mediates that predictive power. Importantly, a comprehensive review of the prior literature (Table A1 in Appendix) demonstrated that, to our knowledge, our mediation result is the first to make a functional distinction between the two brain regions in terms of their contributions to anticipatory motivation.

Recruitment of aINS during outcome anticipation could represent the integration of several different reward processes. Similar anticipatory tasks frequently elicit aINS activity (Knutson and Greer, 2008), and food rewards recruit insular cortex in their sensory and hedonic processing (Craig, 2009). Also, our task - as do others of similar structure - involves outcome uncertainty even though the rewards themselves are certain; that is, participants could not know during the anticipation-phase that they would have a successful-trial. Thus, given that the insular cortex is frequently implicated in tasks with uncertainty, variability in aINS might reflect motivation stemming from gustatory processing, risk processing, or a more integrated signal that is representative of all current affective information for an individual (Singer et al., 2009). Taste and other gustatory processing is generally linked to insular cortex (Kringelbach, 2004), but such processes are hypothesized to be more posterior (Craig, 2009), whereas hedonic and motivational inputs from areas such as NAcc will project to more anterior regions. Our mediation result supports claims that aINS integrates sensory information and forms urges which then feed into the NAcc (Naqvi and Bechara, 2009). Presumably, these affective signals are communicated to NAcc via direct projections from aINS (Chikama et al., 1997; Friedman et al., 2002).

Our results point to several potential and specific roles for NAcc in motivational processing, and make distinctions between NAcc and aINS that are currently absent from the literature. 


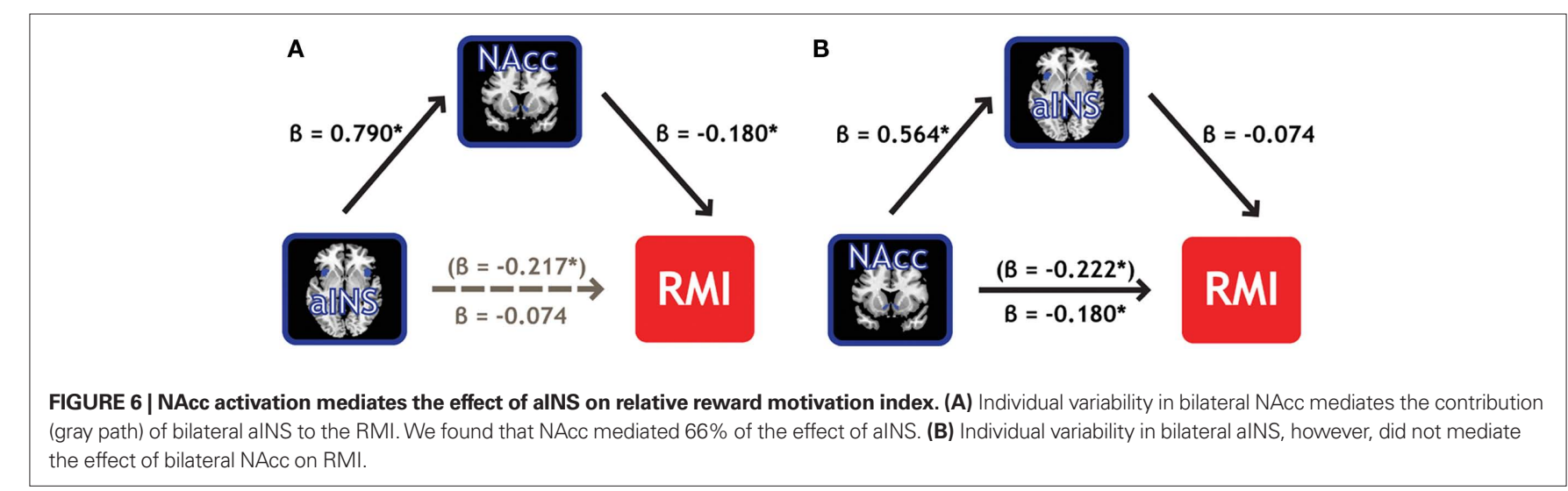

Antecedent signal in NAcc that mediates motivational effects in the aINS corroborates theories of motivation and affect that implicate NAcc. Previous studies involving food have found that NAcc codes preferences for juices that are learned via abstract stimuli (O'Doherty et al., 2006), and trait-based preferences for primary rewards (Cardinal et al., 2002; Beaver et al., 2006). Although aINS and NAcc have previously been hypothesized to play different roles in predicting choice, most differentiations are constrained to potential differences in anticipating appetitive and aversive outcomes (Knutson and Greer, 2008). Our study contains only appetitive stimuli, though, and we found that neural signals during reward anticipation in aINS and NAcc were positively correlated across our two reward modalities (Table 1). This result, along with the mediation analysis, hints that not all motivational information is shared between aINS and NAcc in humans (Craig, 2009; Naqvi and Bechara, 2009). More precisely, our study corroborates much non-human work implicating NAcc as a mediating region for effort-based motivation (Cardinal et al., 2002), translating motivational signals into action (Mogenson et al., 1980).

Distinctions between brain regions - while valuable in terms of better understanding the specific neural circuits of motivational processing, may also be useful in considering more broad decisionmaking phenomena (Clithero et al., 2008). An extension of the results presented here could include mapping anticipatory BOLD signals or RMI onto purchases (Knutson et al., 2007). The simultaneous use of multiple reward categories - a paradigm characteristic that more closely mimics real-world decision environments - is increasing in popularity (Rangel and Hare, 2010; Smith and Huettel, 2010). Exploring the effects of specific combinations of extrinsic incentives on various components of motivation has not been extensively explored, though. For example, if we interpret RMI as a trait for each individual, approximately one-fourth of our participant population demonstrated relatively greater motivation for candy than for money. Our results thus provide evidence that non-monetary rewards (e.g., food) can identify heterogeneity in motivation that would be unobservable using only monetary rewards. Further, the ability to identify underlying motivational differences may be enhanced by employing reward domains outside of money, as demonstrated by the RMI correlations with contrasts specific to candy rewards. We note, however, that there may be important differences between reward sets that include or do not include money; i.e., the presence of monetary rewards can significantly alter a participant's responses to non-monetary outcomes (Heyman and Ariely, 2004).

Additional motivational processes can also have complex effects on decision-making mechanisms. For example, motivation can influence mental effort exerted on a task (Pessoa, 2009). There are also important differences between intrinsic and extrinsic motivators: increases in extrinsic rewards do not always correspond to increases in effort (Kreps, 1997), implying that behavioral measures of motivation likely contain several intrinsic and extrinsic components (Camerer, 2010). We argue that RMI captures a unique component of reward-related motivation because participants were not incentivized to respond with different rates across reward modalities. That is, the external requirement for successful trials (respond before the target disappears) was consistent across reward types; nevertheless, we saw significant variation across individuals in relative reaction times for the two large reward conditions (Figure 2B). Variation in this distinct measure of motivation was tracked by variation in activation in the NAcc. Other fMRI studies have implicated NAcc activity to similar metrics, such as responses to reward cues as representative of effort-based motivational processing (Pessiglione et al., 2007). An additional step will be to unify claims about relative value and motivation with respect to decisions across several different levels: eye movements (Roitman and Shadlen, 2002; Milstein and Dorris, 2007), response rates (Niv et al., 2007), and binary choices between rewards (Chib et al., 2009) all involve motivation. Understanding how motivational claims in one of these classes of decisions translate to others will be crucial for delineating overlapping and distinct neural circuits for behavior (Rangel et al., 2008; Balleine and O’Doherty, 2010).

As the identification of distinct motivational processes continues, the role of NAcc with respect to the neural mechanisms of those processes will improve. Even within the dopaminergic system, different motivational signals may be routed through NAcc (Bromberg-Martin et al., 2010), and across subcortical structures, interactions with cortex are central to processing motivation (Hikosaka et al., 2008). Many studies outline networks involving NAcc and other regions (e.g., amygdala, ventral medial prefrontal cortex, and anterior cingulate cortex) implicated in various types of motivation (Cardinal et al., 2002; Rangel et al., 2008; Kouneiher et al., 2009; Pessoa, 2009). The extent of NAcc as a mediator of 
motivational shifts, and how it might affect the contributions of other brain regions to other types of motivational shifts, merits further investigation.

In summary, we show that reward antecedent signals in both NAcc and aINS predict individual variability in relative motivation across rewards, even in the absence of choice. We employ an expressed measure of relative motivation, response vigor, instead of an inferred value measure. Although it might be intuitive that both regions contribute to motivation independently, we show that information from NAcc mediates information about individual heterogeneity in aINS, suggesting a functional relationship between the two regions. Such a delineation is in line with goals of creating more biologically plausible (Clithero et al., 2008) models of rewardseeking and effortful behavior. In this way, a better understanding

\section{REFERENCES}

Abler, B., Erk, S., and Walter, H. (2007). Human reward system activation is modulated byasingle dose of olanzapine in healthy subjects in an event-related, double-blind, placebo-controlled fMRI study. Psychopharmacology (Berl.) 191, 823-833.

Abler, B., Walter, H., Erk, S., Kammerer, H., and Spitzer, M. (2006). Prediction error as a linear function of reward probability is coded in human nucleus accumbens. Neuroimage 31, 790-795.

Adcock, R. A., Thangavel, A., WhitfieldGabrieli, S., Knutson, B., and Gabrieli, J. D.E. (2006).Reward-motivatedlearning: mesolimbic activation precedes memory formation. Neuron 50, 507-517.

Balleine, B. W., and O'Doherty, J. P. (2010). Human and rodent homologiesin action control: corticostriatal determinants of goal-directed and habitual action. Neuropsychopharmacology 35, 48-69.

Baron, R. M., and Kenny, D. A. (1986). The moderator-mediatorvariable distinction in social psychological research: conceptual, strategic, and statistical considerations. J. Pers. Soc. Psychol. 51,1173-1182.

Beaver, J. D., Lawrence, A. D., Van Ditzhuijzen, J., Davis, M. H., Woods, A., and Calder, A. J. (2006). Individual differences in reward drive predict neural responses to images of food. $J$. Neurosci. 26, 5160-5166.

Beck, A., Schlagenhauf, F., Wustenberg, T., Hein, J., Kienast, T., Kahnt, T., Schmack, K., Hagele, C., Knutson, B., Heinz, A., and Wrase, J. (2009). Ventral striatal activation during reward anticipation correlates with impulsivity in alcoholics. Biol. Psychiatry 66, 734-742.

Beckmann, C. F., Jenkinson, M., and Smith,S.M. (2003). General multilevel linear modeling for group analysis in FMRI. Neuroimage 20, 1052-1063.

Berridge, K. C. (2004). Motivation concepts in behavioral neuroscience. Physiol. Behav. 81, 179-209.

Bjork, J. M., and Hommer, D. W. (2007). Anticipating instrumentally obtained and passively-received rewards: a factorial fMRI investigation. Behav. Brain Res. 177, 165-170.

Bjork, J. M., Knutson, B., Fong, G. W., Caggiano, D. M., Bennett, S. M., and Hommer, D. W. (2004). Incentiveelicited brain activation in adolescents: similarities and differences from young adults. J. Neurosci. 24, 1793-1802.

Brainard,D.H. (1997). The psychophysics toolbox. Spat. Vis. 10, 433-436.

Breiter, H. C., Aharon, I., Kahneman, D., Dale, A., and Shizgal, P. (2001). Functional imaging of neural responses to expectancy and experience of monetary gains and losses. Neuron 30, 619-639.

Breiter, H. C., Gollub, R. L., Weisskoff, R. M., Kennedy, D. N., Makris, N., Berke, J. D., Goodman, J. M., Kantor, H. L., Gastfriend, D. R., Riorden, J. P., Mathew, R. T., Rosen, B. R., and Hyman, S. E. (1997). Acute effects of cocaine on human brain activity and emotion. Neuron 19, 591-611.

Bromberg-Martin, E. S., Matsumoto, M., and Hikosaka, O. (2010). Dopamine in motivational control: rewarding, aversive, and alerting. Neuron 68, 815-834. Camerer, C. F. (2010). Removing financial incentives demotivates the brain. Proc. Natl.Acad.Sci.U.S.A. 107,20849-20850.

Cannon, W. B. (1932). The Wisdom of the Body. New York: W.W. Norton \& Company.

Cardinal, R. N., Parkinson, J. A., Hall, J., and Everitt, B. J. (2002). Emotion and motivation: the role of the amygdala, ventral striatum, and prefrontal cortex. Neurosci. Biobehav. Rev. 26, 321-352.

Carter, R. M., Macinnes, J. J., Huettel, S. A., and Adcock, R. A. (2009). Activation in the VTA and nucleus accumbens increases in anticipation of both gains and losses. Front. Behav. Neurosci. 3:21. doi: 10.3389/neuro.08.021.2009

Chib, V. S., Rangel, A., Shimojo, S., and O’Doherty, J. P. (2009). Evidence for a common representation of decision values for dissimilar goods in human

of motivation can aid in the modeling and prediction of behavioral phenomena, both common (e.g., choosing candy) and complex (e.g., fighting addiction).

\section{ACKNOWLEDGMENTS}

We thank Lindsay Carr for participant recruitment, and Justin Meyer and Adrienne Taren for help with data collection. This work was supported by an Incubator Award from the Duke Institute for Brain Sciences (Scott A. Huettel), by NIMH RC1-088680 (Scott A. Huettel), by an NSF Graduate Research Fellowship (Crystal Reeck), and by NIMH National Research Service Awards F31-086248 (David V. Smith) and F31-086255 (John A. Clithero). The authors have no competing financial interests.

ventromedial prefrontal cortex. $J$ Neurosci. 29, 12315-12320.

Chikama, M., Mcfarland, N. R., Amaral,D. G., and Haber, S.N. (1997). Insular cortical projections to functional regions of the striatum correlate with cortical cytoarchitectonic organization in the primate. J. Neurosci. 17, 9686-9705.

Clithero, J.A., Tankersley, D., and Huettel, S.A. (2008). Foundations of neuroeconomics: from philosophy to practice. PLoS Biol. 6, e298. doi: 10.1371/journal.pbio.0060298

Cohen, M. X., Young, J., Baek, J. M., Kessler, C., and Ranganath, C. (2005). Individual differences in extraversion and dopamine genetics predict neural reward responses. Brain Res. Cogn. Brain Res. 25, 851-861.

Cooper, J. C., Hollon, N. G., Wimmer, G. E., and Knutson, B. (2009). Available alternative incentives modulate anticipatory nucleus accumbens activation. Soc. Cogn. Affect. Neurosci. 4, 409-416.

Cooper, J. C., and Knutson, B. (2008). Valence and salience contribute to nucleus accumbens activation. Neuroimage 39, 538-547.

Craig,A.D. (2009). How do you feel--now? The anterior insula and human awareness. Nat. Rev. Neurosci. 10, 59-70.

Delgado, M. R. (2007). Reward-related responses in the human striatum. Ann. N. Y. Acad. Sci. 1104, 70-88.

Delgado, M. R., Nystrom, L. E., Fissell, C., Noll, D. C., and Fiez, J. A. (2000). Tracking the hemodynamic responses to reward and punishment in the striatum. J. Neurophysiol. 84, 3072-3077.

Dillon, D. G., Holmes, A. J., Jahn, A. L., Bogdan, R., Wald,L.L., and Pizzagalli, D. A. (2008). Dissociation of neural regions associated with anticipatory versus consummatory phases of incentive processing. Psychophysiology 45, 36-49.

Friedman, D. P., Aggleton, J. P., and Saunders, R. C. (2002). Comparison of hippocampal, amygdala, and perirhinal projections to the nucleus accumbens: combined anterograde and retrograde tracing study in the Macaque brain. $J$. Comp. Neurol. 450, 345-365.

Guo, H., and Song, A. W. (2003). Singleshot spiral image acquisition with embedded z-shimming for susceptibility signal recovery. J. Magn. Reson. Imaging 18, 389-395.

Haber, S. N., and Knutson, B. (2010). The reward circuit: linking primate anatomy and human imaging. Neuropsychopharmacology 35, 4-26.

Heyman, J., and Ariely, D. (2004). Effort for payment - a tale of two markets. Psychol. Sci. 15, 787-793.

Hikosaka, O., Bromberg-Martin, E., Hong, S., and Matsumoto, M. (2008). New insights on the subcortical representation of reward. Curr. Opin. Neurobiol. 18, 203-208.

Jenkinson, M., Bannister, P., Brady, M., and Smith, S. (2002). Improved optimization for the robust and accurate linear registration and motion correction of brain images. Neuroimage 17, 825-841. Juckel, G., Schlagenhauf, F., Koslowski, M., Filonov, D., Wustenberg, T., Villringer,A. Knutson,B., Kienast, T., Gallinat,J.,Wrase, J., and Heinz, A. (2006). Dysfunction of ventral striatal reward prediction in schizophrenic patients treated with typical, not atypical, neuroleptics. Psychopharmacology (Berl.) 187,222-228. Kahneman, D., Wakker, P. P., and Sarin, R. (1997). Back to Bentham? Explorations of experienced utility. Quart. J. Econ. 112, 375-405.

Kim, H., Shimojo, S., and O'Doherty, J. P. (2011). Overlapping responses for the expectation of juice and money rewards in human ventromedial prefrontal cortex. Cereb. Cortex 21, 769-776.

Kirsch,P., Schienle,A.,Stark, R., Sammer, G., Blecker, C., Walter, B., Ott, U., Burkart, J., and Vaitl, D. (2003). Anticipation of reward in a nonaversive differential conditioning paradigm and the brain reward system: an event-related fMRI study. Neuroimage 20, 1086-1095.

Knutson, B., Adams, C. M., Fong, G. W., and Hommer, D. (2001a).Anticipation 
of increasing monetary reward selectively recruits nucleus accumbens. $J$. Neurosci. 21, RC159.

Knutson, B., Fong, G. W., Adams, C. M., Varner, J.L., and Hommer, D. (2001b). Dissociation of reward anticipation and outcome with event-related fMRI. Neuroreport 12, 3683-3687.

Knutson, B., Bhanji, J. P., Cooney, R. E., Atlas, L. Y., and Gotlib, I. H. (2008). Neural responses to monetary incentives in major depression. Biol. Psychiatry 63, 686-692.

Knutson, B., Bjork, J. M., Fong, G. W., Hommer, D., Mattay, V. S., and Weinberger,D.R.(2004).Amphetamine modulates human incentive processing. Neuron 43, 261-269.

Knutson, B., Fong, G. W., Bennett, S. M., Adams, C. M., and Homme, D. (2003). A region of mesial prefrontal cortex tracks monetarily rewarding outcomes: characterization with rapid eventrelated fMRI. Neuroimage 18,263-272.

Knutson, B., and Greer, S. M. (2008). Anticipatory affect: neural correlates and consequences for choice. Philos. Trans. $R$. Soc. Lond. B Biol. Sci. 363, 3771-3786.

Knutson, B., Rick, S., Wimmer, G. E., Prelec, D., and Loewenstein, G. (2007). Neural predictors of purchases. Neuron 53, 147-156.

Kouneiher, F., Charron, S., and Koechlin, E. (2009). Motivation and cognitive control in the human prefrontal cortex. Nat. Neurosci. 12, 939-945.

Kreps, D. M. (1997). Intrinsic motivation and extrinsicincentives. Am. Econ. Rev. 87, 359-364.

Kringelbach, M. L. (2004). Food for thought: hedonic experience beyond homeostasis in the human brain. Neuroscience 126, 807-819.

Loewenstein, G. F., and Lerner, J. S. (2003). "The role of affect in decision making," in Handbook of Affective Sciences, eds R. J. Davidson, K. R. Scherer, and G. H. Hill (Oxford: Oxford University Press), 619-642.

Luo, S., Ainslie, G., Giragosian, L., and Monterosso, J. R. (2009). Behavioral and neural evidence of incentive bias for immediate rewards relative to preference-matched delayed rewards. J. Neurosci. 29, 14820-14827.

Maslow, A. H. (1943). A theory of human motivation. Psychol. Rev. 50, 370-396.

Milstein, D. M., and Dorris, M. C. (2007). The influence of expected value on saccadic preparation. J. Neurosci. 27, 4810-4818.

Mogenson, G. J., Jones, D. L., and Yim, C. Y. (1980). From motivation to action: functional interface between the limbic system and the motor system. Prog. Neurobiol. 14, 69-97.

Naqvi, N.H., and Bechara, A. (2009). The hidden island of addiction: the insula. Trends Neurosci. 32, 56-67.
Nestor, L., Hester, R., and Garavan, H. (2010). Increased ventral striatal BOLD activity during non-drug reward anticipation in cannabis users. Neuroimage 49, 1133-1143.

Niv, Y., Daw, N. D., Joel, D., and Dayan, P. (2007). Tonic dopamine: opportunity costs and the control of response vigor. Psychopharmacology (Berl.) 191,507-520.

O’Doherty, J.P., Buchanan, T.W., Seymour, B., and Dolan, R. J. (2006). Predictive neural coding of reward preference involves dissociable responses in human ventral midbrain and ventral striatum. Neuron 49, 157-166.

Pessiglione, M., Schmidt, L., Draganski, B., Kalisch, R., Lau, H., Dolan, R. J., and Frith, C. D. (2007). How the brain translates money into force: a neuroimaging study of subliminal motivation. Science 316, 904-906.

Pessoa, L. (2009). How do emotion and motivation direct executive control? Trends Cogn. Sci. 13, 160-166.

Platt, M. L., and Huettel, S. A. (2008). Risky business: the neuroeconomics of decision making under uncertainty. Nat. Neurosci. 11, 398-403.

Rademacher,L., Krach, S., Kohls, G., Irmak, A., Grunder, G., and Spreckelmeyer, K. N. (2010). Dissociation of neural networks for anticipation and consumption of monetary and social rewards. Neuroimage 49, 3276-3285

Ramnani, N., and Miall, R. C. (2003). Instructed delay activity in the human prefrontal cortex is modulated by monetary reward expectation. Cereb. Cortex 13, 318-327.

Rangel, A., Camerer, C., and Montague, P. R. (2008).A framework for studying the neurobiology of value-based decision making. Nat. Rev. Neurosci. 9, 545-556.

Rangel, A., and Hare, T. (2010). Neural computations associated with goaldirected choice. Curr. Opin. Neurobiol. 20, 262-270.

Roitman, J. D., and Shadlen, M. N. (2002). Response of neurons in the lateral intraparietal area during a combined visual discrimination reaction time task. J. Neurosci. 22, 9475-9489.

Roitman, M.F., Wheeler, R. A., and Carelli, R.M. (2005). Nucleus accumbens neurons are innately tuned for rewarding and aversive taste stimuli, encode their predictors, and are linked to motor output. Neuron 45, 587-597.

Rorden, C., Karnath, H. O., and Bonilha, L. (2007). Improving lesion-symptom mapping. J. Cogn. Neurosci. 19, 1081-1088.

Salamone, J. D., Correa, M., Farrar, A. M., Nunes, E. J., and Pardo, M. (2009). Dopamine, behavioral economics, and effort. Front. Behav. Neurosci. 3:13. doi: 10.3389/neuro.08.013.2009

Samanez-Larkin, G. R., Gibbs, S. E., Khanna, K., Nielsen, L., Carstensen,
L. L., and Knutson, B. (2007) Anticipation of monetary gain but not loss in healthy older adults. Nat. Neurosci. 10, 787-791.

Schlagenhauf, F., Juckel, G., Koslowski, M., Kahnt, T., Knutson, B., Dembler, T., Kienast, T., Gallinat, J., Wrase, J., and Heinz, A. (2008). Reward system activation in schizophrenic patients switched from typical neuroleptics to olanzapine. Psychopharmacology (Berl.) 196, 673-684.

Schmack, K., Schlagenhauf, F., Sterzer, P., Wrase, J., Beck, A., Dembler, T., Kalus, P., Puls, I., Sander, T., Heinz, A., and Gallinat, J. (2008). Catechol-Omethyltransferase val158met genotype influences neural processing of reward anticipation. Neuroimage 42, 1631-1638.

Schultz, W., Apicella, P., Scarnati, E., and Ljungberg, T. (1992). Neuronalactivity in monkey ventral striatum related to the expectation of reward. J. Neurosci. 12, 4595-4610.

Singer, T., Critchley, H.D., and Preuschoff, K. (2009).A common role of insula in feelings, empathy and uncertainty. Trends Cogn. Sci. (Regul. Ed.) 13, 334-340.

Smith, D. V., and Huettel, S. A. (2010). Decision neuroscience: neuroeconomics. Wiley Interdiscip. Rev. Cogn. Sci. 1, 854-871.

Smith, S. M. (2002). Fast robust automated brain extraction. Hum. Brain Mapp. 17, 143-155.

Smith, S. M., Jenkinson, M., Woolrich, M. W., Beckmann, C. F., Behrens, T. E. J., Johansen-Berg, H., Bannister, P. R., De Luca, M., Drobnjak, I., Flitney, D. E., Niazy, R. K., Saunders, J., Vickers, J., Zhang, Y. Y., De Stefano, N., Brady, J. M., and Matthews, P. M. (2004). Advances in functional and structural MR image analysis and implementation as FSL. Neuroimage 23, S208-S219.

Spreckelmeyer, K. N., Krach, S., Kohls, G., Rademacher, L., Irmak, A., Konrad, K., Kircher, T., and Grunder, G. (2009). Anticipation of monetary and social reward differently activates mesolimbic brain structures in men and women. Soc. Cogn. Affect. Neurosci. 4, 158-165.

Staudinger, M. R., Erk, S., and Walter, H. (2011).Dorsolateral prefrontal cortex modulates striatal reward encoding during reappraisal of reward anticipation. Cereb. Cortex. doi: 10.1093/ cercor/bhr041. [Epub ahead of print].

Strohle, A., Stoy, M., Wrase, J., Schwarzer, S., Schlagenhauf, F., Huss, M., Hein, J., Nedderhut, A., Neumann, B., Gregor, A., Juckel, G., Knutson, B., Lehmkuhl, U., Bauer, M., and Heinz, A. (2008). Reward anticipation and outcomesin adult males with attention-deficit/hyperactivity disorder. Neuroimage 39, 966-972.

Villafuerte, S., Heitzeg, M. M., Foley, S., Wendy Yau, W.-Y., Majczenko, K., Zubieta, J.-K., Zucker, R. A., and
Burmeister, M. (2011). Impulsiveness and insula activation during reward anticipation are associated with genetic variants in GABRA2 in a family sample enriched for alcoholism. Mol. Psychiatry. doi: 10.1038/mp.2011.33. [Epub ahead of print].

Waltz,J.A., Schweitzer,J.B., Ross, T. J., Kurup, P. K., Salmeron, B. J., Rose, E. J., Gold, J. M., and Stein, E. A. (2010). Abnormal responses to monetary outcomes in cortex, but not in the basal ganglia, in schizophrenia. Neuropsychopharmacology35, 2427-2439.

Woolrich, M. W., Behrens, T. E., Beckmann, C. F., Jenkinson, M., and Smith, S. M. (2004). Multilevel linear modelling for FMRI group analysis using Bayesian inference. Neuroimage 21, 1732-1747.

Woolrich, M. W., Jbabdi, S., Patenaude, B., Chappell, M., Makni, S., Behrens, T., Beckmann, C., Jenkinson, M., and Smith, S. M. (2009). Bayesian analysis of neuroimaging data in FSL. Neuroimage 45, S173-S186.

Woolrich, M. W., Ripley, B. D., Brady, M., and Smith, S. M. (2001). Temporal autocorrelation in univariate linear modeling of FMRI data. Neuroimage 14, 1370-1386.

Wrase, J., Kahnt, T., Schlagenhauf, F., Beck, A., Cohen, M. X., Knutson, B., and Heinz, A. (2007a). Different neural systems adjust motor behavior in response to reward and punishment. Neuroimage 36, 1253-1262.

Wrase, J., Schlagenhauf, F., Kienast, T., Wustenberg, T., Bermpohl, F., Kahnt, T., Beck,A., Strohle,A., Juckel, G., Knutson, B., and Heinz, A. (2007b). Dysfunction of reward processing correlates with alcohol craving in detoxified alcoholics. Neuroimage 35, 787-794.

Conflict of Interest Statement: The authors declare that the research was conducted in the absence of any commercial or financial relationships that could be construed as a potential conflict of interest.

Received: 05 July 2011; paperpending published: 21 July 2011; accepted: 08 August 2011; published online: 30 August 2011.

Citation: Clithero JA, Reeck C, Carter RM, Smith DV and Huettel SA (2011) Nucleus accumbens mediates relative motivation for rewards in the absence of choice. Front. Hum. Neurosci. 5:87. doi: 10.3389/ fnhum.2011.00087

Copyright (c) 2011 Clithero, Reeck, Carter, Smith and Huettel. This is an open-access article subject to a non-exclusive license between the authors and Frontiers Media $S A$, which permits use, distribution and reproduction in other forums, provided the original authors and source are credited and other Frontiers conditions are complied with. 


\section{APPENDIX}

Our goal was to collect a broad set of representative fMRI studies that includes analyses meant to identify regions implicated in reward anticipation (Table A1). Both of our brain regions of interest, NAcc and aINS, regularly appear in the analyses of the included studies (first and second columns, respectively). So, contrasts that involve the anticipation of gain will likely include both regions. However, we found that only a few studies extend this result to rewards outside of the monetary domain (third column). Even more strikingly, none of the fMRI studies listed in Table A1 make a direct comparison or include a model to distinguish the motivation- or reward-related information in NAcc or aINS (fourth column). In other words, statistical maps from anticipation contrasts in a standard fMRI model will commonly include many brain regions, but the further modeling or testing necessary to make neural or cognitive distinctions between the regions is absent. Examples would include mediation analysis (as in our Figure 6), or models of effective or functional connectivity. Some previous reviews have made distinctions between NAcc and aINS in terms of valence, with negative processing attributed to aINS (Knutson and Greer, 2008), but a within-study distinction in the positive domain is absent from the literature.
Table A1 | Literature search for imaging studies of reward anticipation.

\begin{tabular}{|c|c|c|c|c|c|}
\hline No. & Article & NAcc & alNS & MultR & Mech \\
\hline 1 & Abler et al. (2006) & $x$ & - & - & - \\
\hline 2 & Abler et al. (2007) & $x$ & $x$ & - & - \\
\hline 3 & Adcock et al. (2006) & $x$ & $x$ & - & - \\
\hline 4 & Beck et al. (2009) & $x$ & $x$ & - & - \\
\hline 5 & Bjork et al. (2004) & $x$ & $x$ & - & - \\
\hline 6 & Bjork and Hommer (2007) & $x$ & $x$ & - & - \\
\hline 7 & Breiter et al. (2001) & $x$ & - & - & - \\
\hline 8 & Carter et al. (2009) & $x$ & $x$ & - & - \\
\hline 9 & Cohen et al. (2005) & - & $x$ & - & - \\
\hline 10 & Cooper and Knutson (2008) & $x$ & $x$ & - & - \\
\hline 11 & Cooper et al. (2009) & $x$ & - & - & - \\
\hline 12 & Delgado et al. (2000) & $x$ & $x$ & - & - \\
\hline 13 & Dillon et al. (2008) & $x$ & - & - & - \\
\hline 14 & Juckel et al. (2006) & $x$ & - & - & - \\
\hline 15 & Kim et al. (2011) & - & $x$ & $x$ & - \\
\hline 16 & Kirsch et al. (2003) & $x$ & - & - & - \\
\hline 17 & Knutson et al. (2001a) & $x$ & - & - & - \\
\hline 18 & Knutson et al. (2001b) & $x$ & $x$ & - & - \\
\hline 19 & Knutson et al. (2003) & $x$ & $x$ & - & - \\
\hline 20 & Knutson et al. (2004) & $x$ & $x$ & - & - \\
\hline 21 & Knutson et al. (2008) & $x$ & - & - & - \\
\hline 22 & Luo et al. (2009) & - & $x$ & - & - \\
\hline 23 & Nestor et al. (2010) & $x$ & - & - & - \\
\hline 24 & Rademacher et al. (2010) & $x$ & $x$ & $x$ & - \\
\hline 25 & Ramnani and Miall (2003) & $x$ & - & - & - \\
\hline 26 & Samanez-Larkin et al. (2007) & $x$ & $x$ & - & - \\
\hline 27 & Schlagenhauf et al. (2008) & $x$ & - & - & - \\
\hline 28 & Schmack et al. (2008) & $x$ & - & - & - \\
\hline 29 & Spreckelmeyer et al. (2009) & $x$ & $x$ & $x$ & - \\
\hline 30 & Staudinger et al. (2011) & $x$ & - & - & - \\
\hline 31 & Strohle et al. (2008) & $x$ & - & - & - \\
\hline 32 & Villafuerte et al. (2011) & - & $x$ & - & - \\
\hline 33 & Waltz et al. (2010) & $x$ & - & - & - \\
\hline 34 & Wrase et al. (2007a) & $x$ & $x$ & - & - \\
\hline 35 & Wrase et al. (2007b) & $x$ & - & - & - \\
\hline
\end{tabular}

Our core result (Figure 6 in the main text) provides evidence for a mediation effect between NACC and aINS that involves relative motivation across two reward modalities (money and candy). These two brain regions are frequently implicated in studies that employ similar paradigms (Knutson and Greer, 2008). We collected $\mathrm{fMRl}$ literature on reward anticipation to determine the uniqueness of our findings, focusing on reward anticipation contrasts for positive rewards that implicated NAcC (first column), alNS (second column), and/or included multiple reward modalities (MultR column). We also searched for papers that include joint analyses (e.g., connectivity, mediation) that make claims about a mechanistic relationship (Mech column) between the two regions. An " $X$ " means present, and an "-" indicates not present. 